\title{
PERCEPÇÕES DA EQUIPE DE ENFERMAGEM ACERCA DA HUMANIZAÇÃO EM TERAPIA INTENSIVA
}

\section{Nursing team's perceptions of humanization in intensive care \\ Percepciones del equipo de enfermería sobre la humanización en cuidados intensivos}

\author{
Ariane da Silva Castro (iD \\ Universidade de Cruz Alta - UNICRUZ - Cruz Alta (RS) - Brasil \\ Éder Luís Arboit iD \\ Universidade de Cruz Alta - UNICRUZ - Cruz Alta (RS) - Brasil \\ Gabriela Zenatti Ely iD \\ Universidade de Cruz Alta - UNICRUZ - Cruz Alta (RS) - Brasil \\ Cristiane Appio Motta Dias iD \\ Universidade de Cruz Alta - UNICRUZ - Cruz Alta (RS) - Brasil \\ Jaqueline Arboit iD \\ Universidade Federal de Santa Maria - UFSM - Santa Maria (RS) - Brasil \\ Silviamar Camponogara (iD \\ Universidade Federal de Santa Maria - UFSM - Santa Maria (RS) - Brasil
}

\section{RESUMO}

Objetivo: Conhecer as percepções da equipe de Enfermagem acerca da humanização da assistência em Unidade de Terapia Intensiva. Métodos: Estudo com abordagem qualitativa realizado em 2017, em uma instituição hospitalar cujos participantes foram quatro enfermeiros e oito técnicos de enfermagem atuantes na Unidade de Terapia Intensiva Adulto de um hospital do interior do Rio Grande do Sul, Brasil. A coleta de dados ocorreu por meio de entrevista semiestruturada. Os dados foram analisados pela análise temática, a partir da qual emergiu uma categoria temática, qual seja: O cotidiano de trabalho na Unidade de Terapia Intensiva no contexto da humanização da assistência. Resultados: Os achados revelam que os profissionais percebem a importância da assistência qualificada, embasada numa prática acolhedora e humanizada. Apontam a importância de atender não somente às necessidades biológicas dos pacientes por eles assistidos, mas o uso da comunicação como prática intimamente relacionada com a humanização do cuidado. No entanto, pode-se identificar, por vezes, a falta de conhecimento em relação à política nacional de humanização. Conclusão: $O$ estudo traz subsídios para que os profissionais de Enfermagem possam re(pensar) a sua prática assistencial, tendo em vista aliar a alta densidade tecnológica com a humanização e a segurança do paciente em terapia intensiva.

Descritores: Profissionais de Enfermagem; Humanização da Assistência; Unidades de Terapia Intensiva.

\section{ABSTRACT}

Objective: To get to know the nursing team's perceptions of humanization of care in an Intensive Care Unit. Methods: Study with a qualitative approach performed in 2017 in a hospital institution, whose participants were four nurses and eight nurse technicians working in the Adult Intensive Care Unit of a hospital in the hinterlands of Rio Grande do Sul, Brazil. Data collection was carried out through semi-structured interview. Data were analyzed by means of the thematic analysis, which gave rise to a thematic category, namely: The everyday work in the Intensive Care Unit in the context of the humanization of care. Results: The findings reveal that the professionals perceive the importance of a qualified care, based on a friendly and humanized practice. They highlight the importance of not only meeting the biological needs of the patients under their care, but also using communication as a practice closely related to the humanization of care. Nevertheless, one can sometimes identify the lack of knowledge of the

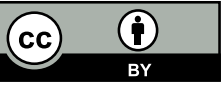


Brazilian humanization policy. Conclusion: This study provides support for nursing professionals to (re)think their health care practice, with a view to combining high technological density with humanization and patient safety in intensive care.

Descriptors: Nurse Practitioners; Humanization of Care; Intensive Care Units.

\section{RESUMEN}

Objetivo: Conocer las percepciones del equipo de Enfermería sobre la humanización de la atención en la Unidad de Cuidados Intensivos. Métodos: Estudio de abordaje cualitativo realizado en 2017 en institución hospitalaria cuyos participantes han sido cuatro enfermeros y ocho técnicos de enfermería de la Unidad de Cuidados Intensivos Adulto de un hospital del interior de Rio Grande de Sur, Brasil. La recogida de datos se dio por entrevista semiestructurada. Los datos han sido analizados por el análisis temático del cual se identificó una categoría temática: El cuotidiano de trabajo de la Unidad de Cuidados Intensivos en el contexto de la humanización de la atención. Resultados: Los hallazgos revelan que los profesionales perciben la importancia de la asistencia de calidad basada en la práctica acogedora y humanizada. Señalan aún la importancia de atender no solamente las necesidades biológicas de los pacientes asistidos por ellos sino también el uso de la comunicación como práctica íntimamente relacionada con la humanización del cuidado. Sin embargo, se puede identificar de cuando en cuando, la falta de conocimiento de la política nacional de humanización. Conclusión: El estudio señala subsidios para que los profesionales de Enfermería puedan re(pensar) su práctica de la atención para aliar la alta densidad tecnológica con la humanización y la seguridad del paciente de cuidados intensivos.

Descriptores: Enfermeras Practicantes; Humanización de la Atención; Unidades de Cuidados Intensivos.

\section{INTRODUÇÃO}

A Unidade de Terapia Intensiva (UTI) surgiu da necessidade de intensificação da assistência à saúde a partir da qualificação de recursos humanos e emprego de materiais e equipamentos para o tratamento de pacientes críticos. Trata-se de um ambiente complexo, com alta concentração tecnológica, recursos humanos qualificados e rotina de assistência sistematizada e contínua(1).

Nessa unidade, há uma possibilidade constante de lidar com situações de emergência e morte, o que se deve ao nível de gravidade dos pacientes assistidos, podendo ser considerado um ambiente hostil pelo excesso de luz e ruídos, excessivos e permanentes ${ }^{(2)}$, procedimentos altamente invasivos, além da restrição dos familiares ${ }^{(3)}$. Isto requer que os profissionais estejam em vigilância para a ocorrência de qualquer intercorrência, o que exige conhecimento especializado e habilidades técnicas em UTI(3) Tendo em vista esse contexto, os pacientes de UTI e familiares acabam, por vezes, sendo assistidos sem o cuidado humanizado.

O Programa Nacional de Humanização da Assistência Hospitalar (PNHAH) foi criado, dispondo, dentre outros assuntos, sobre a humanização da assistência hospitalar pública prestada aos pacientes, assim como sobre o aperfeiçoamento das relações existentes entre usuários e profissionais, entre os profissionais, e entre o hospital e a comunidade, visando aprimorar a qualidade e a eficácia dos serviços prestados ${ }^{(4)}$. Na tentativa de unificar as políticas, em 2003, o PNHAH, juntamente com outros programas de humanização já existentes, teve modificação na Política Nacional de Humanização $(\mathrm{PNH})$, o Humaniza-SUS ${ }^{(5)}$, compreendendo, também, os cenários da Saúde Pública (serviços primárias de atenção) visando aperfeiçoar a eficácia e a qualidade dos serviços de saúde.

O trabalho de Enfermagem em UTI abrange diversas necessidades para qualificar a assistência prestada ao paciente e familiar com foco na humanização, sendo necessário ao profissional unir o saber técnico-científico para prover uma assistência humanizada segura e de melhor qualidade ${ }^{(6)}$. As ações entre os profissionais, a situação crítica dos pacientes e o uso de diversas tecnologias requerem conhecimentos específicos para desenvolver a assistência fundamentada no princípio da integralidade ${ }^{(7)}$, um dos princípios do Sistema Único de Saúde (SUS), o qual considera as pessoas de forma holística, em suas necessidades biopsicossociais ${ }^{(8)}$.

Nessa perspectiva, a Política Nacional de Promoção da Saúde (PNPS), aprovada em 2006 e revisada em 2014, tem como um dos temas transversais a produção de saúde e cuidado, que concebe agregar o tema em redes que propiciem práticas de cuidado humanizadas, que promovam o diálogo, erguendo práticas pautadas na integralidade do cuidado e da saúde ${ }^{(9)}$.

Nessa direção, o cuidado de Enfermagem intensivista, no contexto da humanização, busca atender às necessidades do usuário e de seus familiares, efetivando-se na perspectiva da clínica ampliada e da corresponsabilização do cuidado. Ressalta-se que é um desafio aos profissionais da saúde, em especial na UTI, pelas características dessa unidade já citadas ${ }^{(10)}$. 
O cuidado humanizado objetiva a melhoria do atendimento ao paciente ${ }^{(10)}$. Apesar de vários anos da implementação da $\mathrm{PNH}$, em muitas instituições, as práticas de humanização ainda são consideradas incipientes ${ }^{(11)}$.

Nesse sentido, o cuidado exige dos profissionais a implementação de metodologias que possibilitem que uma melhor atenção seja dispensada ao paciente/familiar. Assim, a humanização do cuidado implica uma otimização da prática de Enfermagem ${ }^{(12)}$.

Assim, a escolha deste tema se deve em função de vivências acadêmicas no decorrer dos estágios curriculares em Enfermagem e, em especial, na terapia intensiva, com vistas à melhoria do cuidado ao paciente internado em UTI. É imprescindível incentivar os profissionais a manifestarem suas opiniões em relação ao cuidado humanizado. Dessa forma, optou-se em realizar o estudo com profissionais que compõem a equipe de Enfermagem, pois são estes que desenvolvem atividades técnicas relacionadas à humanização do atendimento em tempo integral. Diante da problemática exposta e da relevância do cuidado humanizado em UTI, esse estudo tem como questão norteadora: "quais as percepções da equipe de Enfermagem acerca da humanização da assistência em Unidade de Terapia Intensiva"?

O objetivo consiste em conhecer as percepções da equipe de Enfermagem acerca da humanização da assistência em Unidade de Terapia Intensiva.

\section{MÉTODOS}

Pesquisa do tipo qualitativa, por ser considerado o melhor tipo de pesquisa para este estudo, pois atende ao objetivo traçado. Esse tipo de pesquisa investiga as crenças, as percepções e as opiniões que resultam da interpretação humana acerca de suas vivências e sentimentos. Nesse contexto, valoriza-se a percepção dos sujeitos que vivenciam o fenômeno interrogado, como neste estudo ${ }^{(13)}$.

A pesquisa ocorreu em uma UTI Adulto de um hospital do interior do Rio Grande do Sul, Brasil. Trata-se de um hospital privado, de médio porte e com 100 leitos, no qual se internam cerca de 500 pacientes por mês, sendo o corpo clínico constituído por 320 funcionários e cerca de 100 médicos, totalizando mais de 25 especialidades. Do total de leitos, 10 estão situados na UTI Adulto. Para a visita dos familiares nessa unidade, são destinados dois períodos de 30 minutos, no turnos manhã e noite, sendo esse momento acompanhado por enfermeiro(a) e outros profissionais que compõem a equipe de saúde da unidade ${ }^{(14)}$.

Os profissionais que prestam serviço na UTI desse hospital foram convidados a participar da pesquisa. $O$ pesquisador fez o convite de forma presencial, explicando a cada um deles o objetivo do estudo e, em seguida, com os que aceitaram participar, agendou-se uma data para o início da coleta de dados. Os participantes eram enfermeiros e técnicos de enfermagem alocados nos três turnos de trabalho da UTI. Fizeram parte os que ocupavam o cargo de enfermeiro ou técnico de enfermagem há pelo menos seis meses. E não participaram os que estavam afastados do serviço, por motivo de férias ou licença de qualquer natureza, durante o período da coleta de dados. Assim, compuseram a amostra do estudo quatro enfermeiros e oito técnicos de Enfermagem.

A coleta de dados ocorreu em agosto e setembro de 2017, por meio de entrevista semiestruturada(13). A escolha pelo desenvolvimento dessa técnica neste estudo deu-se pela possibilidade de coletar dados subjetivos relacionados aos valores, atitudes e opiniões dos entrevistados, dados que não poderiam ser obtidos por meio de um questionário.

As entrevistas eram compostas de duas etapas: a primeira buscou os dados de identificação dos entrevistados (idade, estado civil, sexo, tempo de atuação na instituição e na UTI, grau de instrução para os técnicos, pós-graduação para os enfermeiros), e a segunda buscou identificar os dados relacionados ao objetivo do estudo, com a seguinte questão norteadora: como você percebe a humanização da assistência de Enfermagem em seu local de trabalho? As entrevistas foram realizadas individualmente, em sala reservada no próprio serviço de saúde, com duração de 20 minutos cada. Foram gravadas em .mp3, assegurando-se um material fidedigno para análise.

O encerramento amostral se deu quando se alcançou o objetivo da pesquisa, levando-se em consideração o critério de saturação temática ${ }^{(15)}$. Posteriormente, as entrevistas foram transcritas em um programa de edição de textos.

Para a sistematização e análise dos dados, utilizou-se a análise temática(13), que possui três fases: pré-análise, exploração do material, e tratamento dos resultados obtidos e interpretação. A primeira fase, pré-análise, é obtida para sistematizar os conceitos iniciais postos pelo quadro referencial teórico e constituir apontadores para a explanação das informações coletadas. A exploração do material, a segunda fase, incide sobre a constituição das operações de codificação, apreciando os recortes dos textos em unidades de registro, a acepção de regras de apuração, e a classificação e associação das informações em categorias simbólicas ou temáticas. A terceira fase envolve o 
tratamento dos resultados e interpretação; incide sobre apreender os conteúdos evidentes e ocultos contidos em todo o material coletado (entrevistas, documentos e observação). Ressaltando os aspectos tidos como análogos e os considerados diferentes, da análise temática emergiu uma categoria, a citar: "O cotidiano de trabalho na Unidade de Terapia Intensiva no contexto da humanização da assistência".

Este estudo respeitou os aspectos éticos da pesquisa envolvendo seres humanos, estando de acordo com a Resolução $n^{\circ} 466 / 2012$ do Conselho Nacional de Saúde ${ }^{(16)}$. Para tanto, os participantes assinaram o Termo de Consentimento Livre e Esclarecido e foram identificados por meio de um código relativo à letra inicial da categoria profissional e sequencialmente numerados, em ordem aleatória de realização das entrevistas, sendo enfermeiro (E1) e técnico de Enfermagem (TE2).

O projeto do presente estudo recebeu aprovação pelo Comitê de Ética em Pesquisa da Fundação Universidade de Cruz Alta UNICRUZ sob o Parecer n. ${ }^{\circ}$ 2.188.659.

\section{RESULTADOS E DISCUSSÃO}

\section{Caracterização dos participantes do estudo}

Entrevistaram-se doze profissionais de Enfermagem, sendo quatro enfermeiros e oito técnicos de Enfermagem. Destes, 11 do sexo feminino. A idade variou de 21 a 42 anos de idade, com média de 33 anos. Quanto ao estado civil dos participantes, dois são casados; dois convivem em regime de união estável; sete são solteiros e um é divorciado. O tempo de atuação na instituição variou de dois a 17 anos, sendo a média de nove anos. Já o tempo de atuação na UTI Adulto variou de 10 meses a 11 anos. Dos doze profissionais, quatro possuíam ensino superior completo; oito, ensino técnico completo; quatro estavam cursando o ensino superior e um cursava especialização.

\section{O cotidiano de trabalho na Unidade de Terapia Intensiva no contexto da humanização da assistência}

Esta categoria remete a compreensão da humanização em ambientes de alta densidade tecnológica. Uma pesquisa recente revela a importância de se compreender a humanização em ambientes de cuidados complexos ${ }^{(17)}$. É preciso entender a dinâmica e a estrutura da instituição, bem como os processos de gestão de recursos (materiais e humanos) e o perfil dos usuários, compreendendo o indivíduo como um ser complexo, singular e capaz de se adequar, dependendo das condições do ambiente em que se encontre e das relações que constitui ${ }^{(17)}$.

Os profissionais de saúde são elementos fundamentais da estrutura organizacional hospitalar e, dessa forma, desenvolvem competências e habilidades inerentes ao seu núcleo profissional. Nesse contexto, há a necessidade de se identificar as competências dos profissionais da UTI, compreendendo que a gerência e a assistência de Enfermagem são funções primordiais no cotidiano do enfermeiro, visando a excelência do cuidado proporcionado ao paciente, família e coletividade ${ }^{(18)}$.

As competências do enfermeiro intensivista incluem: conhecimento, relacionamento interpessoal, liderança, tomada de decisões, trabalho em equipe, comunicação, planejamento, organização e equilíbrio emocional(19). Nessa perspectiva, evidencia-se, no cotidiano dos serviços de saúde, que parte dos profissionais tende a relacionar densidade tecnológica e paciente em situações críticas de vida, muitas vezes, fundamentando-se nas competências do saber/fazer. No entanto, é necessário investimento no desenvolvimento de habilidades de escuta sensível e qualificada, além da expressão não verbal, observação e acolhimento diante das reais necessidades do sujeito.

Pode-se visualizar, por meio dos depoimentos a seguir, a importância da instituição/organização para desenvolver adequadamente as rotinas da unidade:

"Pegamos o plantão, nos organizamos com os pacientes, vemos quem fica com quem. De noite a gente faz rodízio, nunca ficamos com o mesmo paciente. A partir do momento que nos dividimos, a gente se organiza para ver as rotinas da equipe, um vai para farmácia, outro para a Central de Material de Esterilização (CME), outra para a rouparia. Depois disso a gente verifica os sinais vitais, [faz] trocas de fraldas, administração de medicações, presta todos os cuidados relacionados àquele paciente." (TE3)

"Eu recebo plantão, confiro o que é de rotina, como geladeira, lixos, materiais, faço minha visita a cada paciente, faço a avaliação e depois vou para o sistema, fazer as avaliações de risco. Depois, no horário de visita, sempre estamos presentes. Em seguida, supervisionamos o banho, e depois da meia-noite começo a fazer a Sistematização da Assistência de Enfermagem (SAE), prescrição, evolução." (E2)

Diante da alta demanda de atividades assistenciais e de sua complexidade, o cuidado especializado requer do enfermeiro competências específicas e capacidade de trabalho em equipe, visando a melhor resolução das 
necessidades do paciente. Nessa perspectiva, a articulação entre as ações dos diferentes profissionais por meio do trabalho em equipe mostra-se imprescindível para a assistência qualificada e eficaz nessa unidade, estando em consonância com a concepção de cuidado humanizado em UTI(20).

Sistematizar o cuidado implica em utilizar uma metodologia de trabalho embasada cientificamente. A implementação da SAE em UTI contribui significativamente para a qualificação da assistência ao proporcionar uma melhor organização e estruturação da unidade. Essas ações buscam propor maior segurança ao paciente pelo planejamento da atenção à saúde viabilizada pela equipe de enfermeiros, além de outros profissionais, no que tange às ações de núcleo e de campo profissional. Logo, por meio de um instrumento de cuidado, pode viabilizar a troca de informações, imprescindível à assistência singularizada e sistematizada, o que auxilia a efetivar a humanização da assistência( ${ }^{(21)}$.

As atividades do enfermeiro na UTI estão relacionadas à assistência e à gestão da assistência. São compreendidas como atividades gerenciais o estabelecimento de protocolos e rotinas de enfermagem, a administração de recursos tecnológicos e materiais, o desenvolvimento de atividades educativas e a articulação com a equipe multiprofissional e com as demais unidades da instituição hospitalar ${ }^{(22)}$. Identificou-se que o fator mais restritivo do trabalho em equipe multiprofissional em terapia intensiva consiste no desrespeito entre os profissionais. Isto pode ser resultante das relações de hierarquia e falta de conhecimento do fazer de cada profissional, além de falta de comunicação(23).

Assim, a gestão do cuidado perpassa pelos aspectos gerencial e assistencial no processo de trabalho do enfermeiro. Na dimensão gerencial, ele promove ações voltadas para organização do trabalho e de recursos humanos, o que viabiliza as condições para o cuidado ao paciente, bem como para a atuação da equipe de Enfermagem. Na dimensão assistencial, define-se co foco de intervenção com ênfase nas necessidades do usuário, de forma a atendê-las, integralmente( ${ }^{(24)}$.

Também evidencia-se que as atividades do enfermeiro estão centradas em papéis administrativos e com pouca articulação com o cuidado. Contudo, faz-se necessária a articulação e integração de outros aspectos, como gestão, cuidado, liderança, comunicação, interação, tomada de decisão e cooperação. Esses elementos são considerados atributos essenciais da gestão do cuidado em enfermagem ${ }^{(25)}$. Nesse sentido, os entrevistados relatam algumas rotinas de trabalho na UTI, contudo exaltam que o paciente sempre está em primeiro lugar:

"Alguns dias são mais agitados. O básico é chegar, receber plantão, avaliar paciente, realizar Sistematização da Assistência de Enfermagem, resolver as pendências do setor e passar informações dos pacientes aos familiares." (E1)

"Dispomos de uma carga horária de 6 horas, sendo 15 minutos de intervalo. O cotidiano de trabalho segue bastante as rotinas, mas, por vezes, a rotina pode ser diferente, mas procuramos fazer o melhor para o paciente, sempre trabalhando em equipe para desenvolver o cuidado ao paciente." (TE2)

A UTI é uma unidade complexa; um ambiente que, muitas vezes, coloca paciente e familiar em condição de fragilidade. Além disso, essa unidade requer a integração entre os diversos profissionais que compõem a equipe multi e interdisciplinar, de modo a proporcionar a realização de cuidados alinhados com as reais necessidades dos pacientes, tendo em vista a sua condição clínica e necessidades enquanto sujeito. Visa proporcionar, ainda, maior segurança aos familiares, pois estes não dispõem da possibilidade de permanecer na unidade em tempo integral e, muitas vezes, precisam se deslocar por longas distâncias para visitá-lo(2).

Outro aspecto que precisa ser considerado é que esses deslocamentos geram custos e, em algumas ocasiões, o familiar não dispõe de recursos financeiros para isso. Diante dessa situação, o enfermeiro tem um papel importante também no sentido de acolher o familiar do paciente e proporcionar momentos que possam estreitar os vínculos entre os envolvidos e auxiliar na elaboração de estratégias para que esses vínculos possam ser fortalecidos( ${ }^{(6)}$.

Pode-se inferir, por meio dos relatos dos participantes, que percebem a necessidade de desenvolver uma assistência mais humanizada na unidade de terapia intensiva, pois evidenciam fragilidades em relação à base teórica da humanização:

"Eu sempre digo assim, 'eu escolhi esta profissão e sou bem feliz'. Gosto muito do que eu faço, mas, quando comecei na UTI, tive dificuldade, porque aqui é uma realidade bem difícil, os pacientes são bem críticos. Mas eu aprendi que são pessoas que necessitam mais ainda do cuidado humanizado." (TE4)

"Humanização é uma palavra de vários significados. [...] Acredito que tenha um pouco de humanização, mas, na parte de Enfermagem, tem que desenvolver muito. Humanização, a maioria entende uma coisa, mas o contexto é totalmente diferente. Não dá para dizer que não tenha um pouco, nem que seja um pouco, tem no atendimento ao paciente, nos cuidados principalmente. Acho que é um assunto bonito de se falar, mas muito pouco trabalhado." (TE5) 
"De acordo com a nossa experiência, com o passar do tempo perde-se um pouco da sensibilidade, deixando um pouco de lado o envolvimento. Levando em consideração o tempo em que estou na unidade, nos tornamos mais frios. Mas aprendemos o que é humanizar nosso atendimento todo dia." (TE7)

Os relatos supracitados vão ao encontro de estudo recente que identificou que os profissionais da saúde, mesmo referindo não ter conhecimento do conteúdo da Política Nacional de Humanização, trazem para sua prática diária valores como respeito, dignidade e amor ao próximo, assim tornando mais humanas as suas atividades diárias ${ }^{(3)}$.

A perda da sensibilidade, citada por um entrevistado da presente pesquisa, pode estar relacionada à tecnologia utilizada pelos profissionais de saúde nos serviços para auxiliar na manutenção da vida, o que, por vezes, pode ser um aspecto positivo. Por outro lado, pode ser negativo, pois a diversidade tecnológica, especialmente em UTI, pode fragilizar a prática da humanização da assistência pelos profissionais, visto que há uma gama de procedimentos assistenciais que requerem o uso dessas tecnologias ${ }^{(10)}$, o que torna a assistência cada vez mais mecanizada e afasta o profissional do paciente.

Sob esse ponto de vista, é necessário refletir acerca das ações e interações no contexto dos serviços de saúde: sobre o que, como e quando falar; o que, como e quando olhar; como se posicionar e tocar; sobre o ato que excede o mero manuseio do corpo do outro. É importante procurar compreender atentamente a mensagem, verbalizada ou não, do que o outro tenta transmitir, para que se possa atender às suas necessidades ${ }^{(25)}$.

Outro aspecto importante evidenciado nos depoimentos consiste na comunicação, a qual está intimamente relacionada à humanização do cuidado:

"É uma equipe bem humana. Conseguimos conversar com os pacientes, pegar na mão. Aqui podemos ter um atendimento mais humanizado por ser um atendimento mais intensivo [...] Estamos mais perto do paciente para conversar e auxiliar no que for necessário." (TE8)

"É a comunicação entre gestor/colaborador na elaboração dos processos de trabalho." (E4)

A comunicação é um importante instrumento dentro da UTI e deve envolver pacientes, familiares, profissionais e a mídia. Boas relações pessoais e um ambiente de comunicação tolerante e aberto são identificados como fatores que favorecem a qualidade e a atenção humana ${ }^{(26)}$. É preciso que essa comunicação ocorra e beneficie todo o conjunto, que visa, principalmente, o bem-estar e saúde do paciente. Nessa perspectiva, a comunicação pode ser direcionada, tanto para o próprio paciente quanto para os familiares e entre a equipe ${ }^{(27)}$.

Evidenciaram-se, também, nos depoimentos, algumas questões relacionadas à $\mathrm{PNH}$ e aos direitos do paciente:

“(...) deve acontecer, pois é uma unidade de muito sofrimento, na maioria das vezes, para os familiares e para o paciente, onde precisamos acolher ambos com dedicação, respeito e profissionalismo. Compreender a necessidade de cada um, atendendo-os da melhor forma possível. A Política Nacional de Humanização é para melhorar a comunicação de diferentes profissionais, como gestores, e também dos usuários, para que possa ser compartilhado entre todas as pessoas, para que seja seguido o mesmo modo de cuidar, e organização do trabalho." (E3)

“(...) sei que são direitos do paciente e nada mais." (TE1)

“(...) o paciente tem que estar ciente dos direitos que ele tem. Assim como nós temos um código de ética que temos que seguir para prestar o serviço, (...) deixar tudo dentro do ambiente de trabalho, não sair falando o que acontece aqui dentro. Então, a política de humanização é mais ou menos isso, o cuidado que a gente tem que ter com o paciente e atender tudo o que o paciente tem direito." (E2)

Os participantes percebem que a humanização em terapia intensiva perpassa a relação com a ética e o acolhimento dos familiares e pacientes, assim como o respeito aos seus direitos. Apesar de aparecerem dificuldades, por parte dos profissionais, em conceituar humanização, trazem em seus modos de expressão e vivências suas opiniões a respeito do tratamento humanizado ou não. Os profissionais de saúde investigados dizem compreender os preceitos da $\mathrm{PNH}$ e asseguram executar em suas práticas assistenciais tais orientações, apesar de relatarem que ainda existem muitas falhas no caminho ideal para uma efetiva humanização nos serviços de saúde ${ }^{(6)}$.

Um estudo apontou que a assistência aos pacientes na UTI é pertinente ao cuidado intensivo por parte da equipe profissional. Contudo, esse cuidado demanda não só uma assistência técnica com dimensionamento biológico, mas uma assistência integral com os pacientes, tratando-os como seres humanos, com respeito, afetividade e dedicação( ${ }^{(28)}$.

Nesse sentido, tem-se a necessidade de se investir na relação profissional-paciente-familiar. O profissional deve ser capaz de oferecer as informações necessárias e demonstrar paciência, atenção e carinho na interação com o 
paciente ${ }^{(21)}$. Evidenciou-se que o ambiente restrito pode ser benéfico, o que pode favorecer o cuidado, com ações mais humanizadas e acolhedoras:

"Ambiente fechado, com menor número de pacientes, contato direto com familiares, tendo a possibilidade de um melhor acolhimento." (TE6)

Estudo recente revela que humanizar não se restringe ao acolher com simpatia; também envolve o estabelecimento de relações, as condições de trabalho e os espaços de escuta para todos(as) os(as) atores(as) envolvidos(as) ${ }^{(29)}$. Isto possibilita escolhas em uma perspectiva clínica e projetos de vida do sujeito, o que implica na corresponsabilidade do processo saúde-doença. O ambiente da UTI deve ser bem apresentável, harmonioso, agradável, organizado e limpo, proporcionando conforto e bem-estar aos pacientes, familiares e profissionais, o que vai ao encontro do conceito de ambiência proposto pela $\mathrm{PNH}$, segundo o qual é importante criar espaços saudáveis e acolhedores, que proporcionem privacidade aos envolvidos nesse processo de cuidado ${ }^{(10)}$.

Ao se colocar no lugar do paciente, o profissional de saúde pode se identificar com os sentimentos pela doença e reconhecer que, além da dimensão patológica, há fatores emocionais e sociais importantes:

“(...) a identificação com o paciente pode levar a gente a ter sentimentos como medo ou angústia, o que nos leva a repensar acerca de nossas ações de cuidado ao outro ser humano. (...) entendo que muitos são os elementos que contribuem para o processo de cura do paciente, como ouvir, conversar, tocar, respeitar e comprometer-se." (E1)

Contudo também foi citada a restrição do contato entre profissional e paciente, e entre este e seu familiar, como uma dificuldade no que tange à humanização:

"Contato restrito do profissional de saúde com o familiar e pouco contato do familiar com o paciente." (TE1)

O distanciamento pode ser um fator dificultador para os profissionais, pacientes e seus familiares, pois gera ansiedade e medo. Diante desse aspecto, a comunicação consiste em uma estratégia para humanizar o cuidado. Esta deve ser direcionada aos pacientes, sejam conscientes, sejam inconscientes, e aos seus familiares, tendo em vista informá-los acerca do contexto e quadro clínico do familiar internado na UTI e acolher sua angústia, esperança e medo ${ }^{(20)}$.

Em estudo brasileiro, o único momento proporcionado ao contato dos pacientes com familiares é o intervalo limitado destinado à visita ${ }^{(30)}$. Nesse momento, os familiares explicitam seus anseios e emoções, suas dúvidas com relação à evolução da doença, suas preocupações e reflexos da quebra de papéis sociais proporcionada pela internação. A maioria dos pacientes em estado grave não responde satisfatoriamente aos estímulos, o que remete os familiares aos profissionais de saúde.

Neste contexto, as informações apresentadas pelos profissionais de saúde no momento da visita devem ser esclarecedoras e prestadas de forma empática. Isto ressalta uma boa comunicação dos profissionais e o entendimento dos aspectos que envolvem a relação entre todos os envolvidos no processo de cuidado ${ }^{(30)}$. Logo, é essencial promover a relação terapêutica produzida por meio do contato entre família e paciente.

Ressalta-se que o atual estudo apresenta limitações, que incluem principalmente o fato de ter envolvido apenas profissionais da equipe de Enfermagem que atuam em uma unidade de terapia intensiva de um único hospital, o que dificulta a generalização dos resultados.

Por fim, os achados, ao revelarem que os entrevistados acreditam que a prática deve ser acolhedora e humanizada, sinalizam que o paciente deve ser acolhido não somente nas suas necessidades biológicas, mas no uso da comunicação, sendo relevante como prática intimamente relacionada à humanização do cuidado. No entanto relatam que sentem dificuldade para reconhecer, algumas vezes, alguns aspectos da Política Nacional de Humanização.

Como a Política Nacional de Humanização tem o intuito de formar profissionais cuja prática deve ser pautada em ações com eficiência técnica, científica e humana, de forma ética, respeitando a individualidade do paciente e com olhar holístico(5); e, por sua vez, a Politica Nacional de Promoção da Saúde sugere o desafio de reorientar os serviços de saúde a suplantar a fragmentação do assistir a doença e direcionar-se na perspectiva da atenção integral às pessoas em suas necessidades, numa relação dialógica do cuidar/ser cuidado, do ensinar/aprender ${ }^{(31)}$, sugere-se a realização de cursos de aperfeiçoamento para toda a equipe desses profissionais da UTI, a fim de minimizar os problemas por eles ressaltados. 
Inicialmente, a equipe deve compreender o que seja a estratégia de humanização, um processo de interferência na produção de saúde através do investimento em um novo tipo de interação entre sujeitos, qualificando vínculos interprofissionais e destes com os usuários do sistema, sustentando a construção de novos dispositivos institucionais ${ }^{(32)}$ e, dessa forma, facilitando a promoção da saúde.

Diante dessa realidade, verifica-se o quão é importante a humanização no cuidado ao paciente em situações críticas de forma sistemática, desde a graduação, contemplando, acima de tudo, um processo de desenvolvimento de competências ético-morais que norteiem suas futuras práticas ${ }^{(33)}$.

Nesse contexto, deve-se pactuar estratégias e metodologias de ensino e aprendizagem que viabilizem as ações pretendidas, sendo preciso buscar um fedeeback constante em um processo dinâmico dos sujeitos, entre a equipe de saúde, gestão, familiares e pacientes. O impacto da humanização do atendimento na UTI, seria portanto, avaliado dessa forma, propondo melhorias na qualidade da atenção à saúde, na otimização de recursos públicos e na segurança do paciente.

\section{CONSIDERAÇÕES FINAIS}

Os achados revelam que os profissionais entrevistados percebem a importância da assistência qualificada, embasada numa prática acolhedora e humanizada.

Percebem, também, a importância de atender não somente às necessidades biológicas dos pacientes por eles assistidos, mas de utilizarem a comunicação como prática intimamente relacionada à humanização do cuidado. Pode-se identificar, no entanto, por vezes, a falta de conhecimento em relação à Política Nacional de Humanização.

O estudo traz subsídios para que os profissionais de Enfermagem possam re(pensar) a sua prática assistencial, tendo em vista aliar a alta densidade tecnológica com a humanização e a segurança do paciente em terapia intensiva.

\section{CONFLITOS DE INTERESSE}

Os autores declaram que não houve conflitos de interesses.

\section{CONTRIBUIÇÕES}

Ariane da Silva Castro e Éder Luís Arboit contribuíram com a concepção e o projeto, a revisão crítica relevante do conteúdo intelectual, a coleta e análise dos dados e a aprovação final da versão a ser publicada; Gabriela Zenatti Ely, Cristiane Appio Motta Dias, Jaqueline Arboit e Silviamar Camponogara contribuíram com a análise e interpretação dos dados, a revisão crítica relevante do conteúdo intelectual e a aprovação final da versão a ser publicada.

\section{REFERÊNCIAS}

1. Santos ES, Gastaldi AB, Montezeli JH, Garanhani ML. Acolhimento e processo educativo em saúde a familiares de pacientes internados em UTI adulto. Ciênc Cuid Saúde. 2016;15(4):639-46.

2. Escudero D, Viña L, Calleja C. Por una UCl de puertas abiertas, más confortable y humana. Es tiempo de cambio. Med Intensiva. 2014;38(6):337-402.

3. Machado ER, Soares NV. Humanização em UTI: sentidos e significados sob a ótica da equipe de saúde. Rev Enferm do Cent-Oeste Min. 2016;6(3):2342-8.

4. Ministério da Saúde (BR). Manual do Humaniza SUS [Internet]. 2003 [acesso em 2008 Fev 5]. Disponível em: http://bvsms.saude.gov.br/bvs/publicacoes/humanizaSus.pdf.

5. Ministério da Saúde (BR). Programa Nacional de Humanização da Assistência Hospitalar. Brasília: Ministério da Saúde; 2001.

6. Luiz FF, Caregnato RCA, Costa MR. Humanização na terapia intensiva: percepção do familiar e do profissional de saúde. Rev Bras Enferm. 2017;70(5):1095-103.

7. Massaroli R, Gue Martini J, Massaroli A, Delacanal Lazzari D, Nunes de Oliveira S, Pedroso Canever B. Trabalho de enfermagem em unidade de terapia intensiva e sua interface com a sistematização da assistência. Esc Anna Nery Rev Enferm. 2015;19(2):252-8. 
8. Souza-Silva JC, Martins CA, Barbosa MA. Rede de atenção à saúde: percepção de usuárias do Sistema Único de Saúde. Rev Bras Promoç Saúde. 2016;29(Supl):44-50.

9. Malta DC, Reis AAC, Jaime PC, Morais OL Neto, Silva MMA, Akerman M. Brazil's Unified Health System and the National Health Promotion Policy: prospects, results, progress and challenges in times of crisis. Ciênc Saúde Colet. 2018;23(6):1799-809.

10. Ministério da Saúde (BR), Secretaria de Assistência a Saúde. Cartilha Humaniza SUS. Política Nacional de Humanização - PNH. Brasília: Ministério da Saúde; 2015.

11. Mongiovi VG, Anjos RCCBL, Soares SBH, Lago-Falcão TM. Reflexões conceituais sobre humanização da saúde: concepção de enfermeiros de Unidades de Terapia Intensiva. Rev Bras Enferm. 2014;67(2):306-11.

12. Pascuci L, Meyer V Jr , Nogueira EE, Forte LT. Humanization in a hospital: a change process integrating individual, organizational and social dimensions. J Health Manag. 2017;19(2):1-20.

13. Minayo MCS. O desafio do conhecimento: pesquisa qualitativa em saúde. 14ª ed. São Paulo: Hucitec; 2014.

14. Hospital Regional Santa Lúcia [Internet]. 2018 [acesso em 2019 Fev 14]. Disponível em: https://www. hospitalsantalucia.com.br

15. Fontanella BJB, Ricas J, Turato ER. Amostragem por saturação em pesquisas qualitativas em saúde: contribuições teóricas. Cad Saúde Pública. 2008;24(1):17-27.

16. Brasil. Ministério da Saúde, Conselho Nacional de Saúde. Resolução n 466, de 12 de dezembro de 2012: diretrizes e normas regulamentadoras de pesquisas envolvendo seres humanos. Diário Oficial da União; Brasília, 13 Jun 2013.

17. Sanches RCN, Gerhardt PC, Rêgo AS, Carreira L, Pupulim JSL, Radovanovic CAT. Percepções de profissionais de saúde sobre a humanização em unidade de terapia intensiva adulto. Esc Anna Nery Rev Enferm. 2016;20(1):48-54.

18. Soares MI, Resck ZMR, Terra FS, Camelo SHH. Sistematização da assistência de enfermagem: facilidades e desafios do enfermeiro na gerência da assistência. Esc Anna Nery Rev Enferm. 2015;19(1):47-53.

19. Correio RAPPV, Vargas MAO, Carmagnani MAS, Ferreira ML, Luz KR. Desvelando competências do enfermeiro de terapia intensiva. Enferm Foco. 2015;6(1/4):46-50.

20. Evangelista VC, Domingos TS, Siqueira FPC, Braga EM. Equipe multiprofissional de terapia intensiva: humanização e fragmentação do processo de trabalho. Rev Bras Enferm. 2016;69(6):1099-107.

21. Oliveira APC, Coelho MEAA, Almeida VCF, Lisboa KWSC, Macêdo ALS. Sistematização da assistência de enfermagem: implementação em uma unidade de terapia intensiva. Rev RENE. 2012;13(3):601-12.

22. Chaves LDP, Laus AM, Camelo SH. Ações gerenciais e assistenciais do enfermeiro em unidade de terapia intensiva. Rev Eletrônica Enferm. 2012;14(3):671-8.

23. Araujo JD Neto, Silva ISP, Zanin LE, Andrade AP, Moraes KM. Profissionais de saúde da unidade de terapia intensiva: percepção dos fatores restritivos da atuação multiprofissional. Rev Bras Promoç Saúde. 2016;29(1):43-50.

24. Mororó DDS, Enders BC, Lira ALBC, Silva CMB, Menezes RMP. Análise conceitual da gestão do cuidado em enfermagem no âmbito hospitalar. Acta Paul Enferm. 2017;30(3):323-32.

25. Cardoso OP Jr, Pinto JMS. Quando a vida começa diferente: cuidado postural no cotidiano da equipe multiprofissional em terapia intensiva pediátrica. Tempus. 2016;10(4):83-100.

26. Rico LR, Marsans MC, Márquez CM, Borrás AM, Riba LS, Savall DT, et al. Relaciones interdisciplinarias y humanización en las unidades de cuidados intensivos. Enferm Intensiva. 2006;17(4):141-53.

27. Andrade CG, Costa SFG, Lopes MEL. Cuidados paliativos: a comunicação como estratégia de cuidado para o paciente em fase terminal. Ciênc Saúde Coletiva. 2013;18(9):2523-30.

28. Backes MTS, Erdmann AL, Büscher A. The Living, dynamic and complex environment care in intensive care unit. Rev Latino-Am. Enfermagem. 2015;23(3):411-8. 
29. Silveira de Carli B, Ubessi LD, Pettenon MK, Righi LB, da Rosa Jardim VM, Fernandes Stumm EM. The humanization theme in intensive care in health studies. Rev Pesqui Cuid Fundam. 2018;10(2):326-33.

30. Félix TA, Ferreira FV, Oliveira EN, Eloia SC, Gomes BV, Eloia SMC. Prática da humanização na visita em unidade de terapia intensiva. Revista Enfermagem Contemporânea. 2014;3(2):143-53.

31. Ministério da Saúde (BR). Política Nacional de Promoção da Saúde: documento para discussão. Brasília: MS; 2002.

32. Deslandes SF. Análise do discurso oficial sobre a humanização da assistência hospitalar. Cienc Saúde Colet. 2004;9(1):7-14.

33. Figueiredo MCCM, Ferreira TN, Almeida FCA, Araújo AM, Araújo PE, Souza KBS, et al. Cuidado humanizado ao paciente crítico: uma revisão integrativa. Rev Saúde Ciênc [Internet]. 2018 [acesso em $2019 \mathrm{Fev}$ 18];7(1):94-101. Disponível em: http://www.ufcg.edu.br/revistasaudeeciencia/index.php/RSC-UFCG/article/ view/513

\section{Endereço do primeiro autor:}

Ariane da Silva Castro

Universidade de Cruz Alta - UNICRUZ

Rodovia Municipal Jacob Della Méa, Km 5.6

CEP: 98005-972 - Cruz Alta - RS - Brasil

E-mail: arianecastro06@gmail.com

\section{Endereço para correspondência:}

Éder Luiz Arboit

Rua Protásio Mendes Castanho, 363

Bairro: Sulgon

CEP: 98300-000 - Palmeira das Missões - RS- Brasil

E-mail: earboit@unicruz.edu.br

Como citar: Castro AS, Arboit EL, Ely GZ, Dias CAM, Arboit J, Camponogara S. Percepções da equipe de enfermagem acerca da humanização em terapia intensiva. Rev Bras Promoç Saúde. 2019;32:8668. 